\title{
A COMPARATIVE STUDY ON SQUARE AND CIRCULAR HIGH STRENGTH CONCRETE-FILLED STEEL TUBE COLUMNS
}

\author{
S. Guler ${ }^{1, *}$ A. Çopur ${ }^{2}$ and M. Aydogan ${ }^{3}$ \\ ${ }^{1}$ PhD, Department of Civil Engineering, Istanbul Technical University, Istanbul, Turkey \\ ${ }^{2}$ MSc, Department of Civil Engineering, Istanbul Technical University, Istanbul, Turkey \\ ${ }^{3}$ Professor, Department of Civil Engineering, Istanbul Technical University, Istanbul, Turkey \\ *(Corresponding author: E-mail: : gulersoner@yandex.com)
}

Received: 19 December 2012; Revised: 5 February 2013; Accepted: 28 February 2013

\begin{abstract}
This paper investigates the behavior of axially loaded square and circular high strength concrete-filled steel tube (CFST) columns. The effects of steel tube thickness and bond strength between the steel tube and the concrete core on axial load capacity and ductility are studied. The performance indices named ductility index (DI), strength enhancement index (SI) and concrete contribution ratio (CCR) are also evaluated for the square and the circular high strength CFST columns. The experimental results are compared with the values estimated by current design codes such as Eurocode 4 (EC4) and AISC-LRFD (1999). The results show that the difference of the axial load capacity due to loss of bonding is significant for both of the square and the circular high strength CFST columns. However, this difference is equal for both of the square and the circular columns with $\mathrm{H} / \mathrm{t}$ or $\mathrm{D} / \mathrm{t}$ smaller than 20. The EC4 design code, contrary to the AISC-LRFD (1999), generally overestimates the axial load capacity of the square and the circular high strength CFST columns.
\end{abstract}

Keywords: High strength concrete, concrete-filled steel tube stub columns, axial load capacity, D/t ratio, bond effect, design codes, performance indices

\section{INTRODUCTION}

Concrete-filled steel tube (CFST) columns are widely used in the construction of high-rise buildings, bridges, subway platforms, and barriers. The CFST columns provide excellent static and earthquake-resistant properties such as high strength, high ductility, high stiffness, and large energy-absorption capacity. The CFST columns provide some advantages of both steel and concrete. The steel tube assists to carry the axial load and confines the concrete core. Furthermore, the steel tube annihilates the permanent formwork, which reduces construction time, while the concrete core takes the axial load and avoids or delays local buckling of the steel tube (Lu and Zhao [1]).

Recently, there is an increase in use of high strength concrete (HSC) in major construction projects such as high-rise buildings, offshore oil platforms and bridges. HSC is known as a material that is generally associated with low water to cement ratio, high durability, low permeability and a high compressive strength in the range of over $60 \mathrm{MPa}$. In the recent years using chemical admixtures and silica fumes that partially replace cement as well as applying improved design methods and mixing techniques allows the engineers to produce concrete with much higher compressive strength. Concrete with a compressive strength over $100 \mathrm{MPa}$ can be easily produced commercially using conventional methods and materials. As a result, today HSC has much better performance compared to normal strength concrete. That is why it is commonly used in the construction practice in many countries all over the world (Shah and Ribakov [2]).

One of the major concerns related to HSC is the need of sufficient confinement. Poisson ratio is slightly less and the amount of shrinkage is higher of HSC compared with low and normal strength concrete. Because of those effects, the confining effect of the steel tube to the high strength concrete is not as much as the low and normal strength concrete. Hence, the difference of the axial 
load capacity due to loss of bonding is critical for high strength CFST columns. There are many studies to investigate the bond effect for CFST columns with concrete compressive strength up to $100 \mathrm{MPa}$. Roeder et al. [3] investigate that the importance of bond stress and interface conditions on the axial load capacities of the circular CFST columns with concrete compressive strength varies from 28.6 MPa to $47.2 \mathrm{MPa}$. The test results show that the bond capacity, for the circular CFST columns, is smaller with large diameter tubes and large diameter-to thickness $(\mathrm{D} / \mathrm{t})$ ratios. An experimental study is conducted on circular high strength CFST columns with cylinder concrete strength of $65 \mathrm{MPa}$ by (Johansson and Gylltoft [4]). The test results imply that the bond strength has no influence on the behavior when the steel and concrete sections are loaded simultaneously. On the contrary, for the columns with the load applied only to the concrete section, the bond strength highly affected the confinement effects and, consequently, the mechanical behavior of the columns. Giakoumelis and Lam [5] examine 15 circular CFST columns with concrete compressive strength of 30,60 , and $85 \mathrm{MPa}$. Contrary to the results of Johansson and Gylltoft [4], the results reveal that the difference of the axial load capacity due to loss of bonding is negligible for low or normal concrete strength while it is critical for the high strength concrete. The difference of the axial load capacity for the high strength CFST columns is $17 \%$. Although there are lots of studies on CFST columns with concrete compressive strength up to $100 \mathrm{MPa}$, there still needs further analyses on the CFST columns with concrete strength over $100 \mathrm{MPa}$. To fill such a gap in the literature, Guler et al. [6] study the bond effect on the behavior of the square high strength CFST columns with concrete compressive strength of $115 \mathrm{MPa}$ depending on the different steel tube thickness. The test results clearly show that the difference of the axial load capacity due to loss of bonding is significant for the square high strength CFST columns. The biggest difference of the axial load capacity is $14 \%$ for the square high strength CFST columns with $3 \mathrm{~mm}$ steel tube thickness.

\section{$1.1 \quad$ Objective}

The first aim of this study is to compare the difference of the axial load capacity due to the bond effect for the square and the circular high strength CFST columns with concrete strength over 100 $\mathrm{MPa}$ depending on the different steel tube thickness. Secondly, some important parameters the ductility index (DI), the strength enhancement index (SI) and the concrete contribution ratio (CCR) are compared and evaluated for the square and the circular high strength CFST columns. Finally, the axial load capacities of the high strength CFST columns are compared with the values predicted by the EC4 [7]; the American Institute of Steel Construction- Load Resistance Factor Design AISC-LRFD [8] design codes.

\section{EXPERIMENTAL PROGRAM}

Totally, 40 the square and the circular high strength CFST columns are tested under monotonic axial compression. The steel tube and the concrete are simultaneously loaded. To achieve this, the steel plates with thickness of $10 \mathrm{~mm}$ are welded top and bottom surfaces of the square and the circular CFST columns. The specimens are separated as greased and non-greased specimens to investigate the bond effect depending on the different steel tube thickness. The nominal steel tube thickness of the specimens is selected $3 \mathrm{~mm}, 4 \mathrm{~mm}$, and $5 \mathrm{~mm}$ for the square columns and $3 \mathrm{~mm}, 4$ $\mathrm{mm}$, and $6 \mathrm{~mm}$ for the circular ones. The height-to-thickness $(\mathrm{H} / \mathrm{t})$ ratio of the square columns and diameter-to-thickness ratio (D/t) ratio of the circular columns vary from 19 to 37.9. All the specimens are $400 \mathrm{~mm}$ in length to prevent the slenderness effect and to ensure that the specimens behave as stub columns. A thin layer of non-shrinkage cementitious mortar is poured on the top surface of the concrete to provide the concrete core and the steel tube are loaded simultaneously. All the tests are performed three months after casting of concrete. The square and the circular specimens before concrete-filled are shown in Figure 1. 


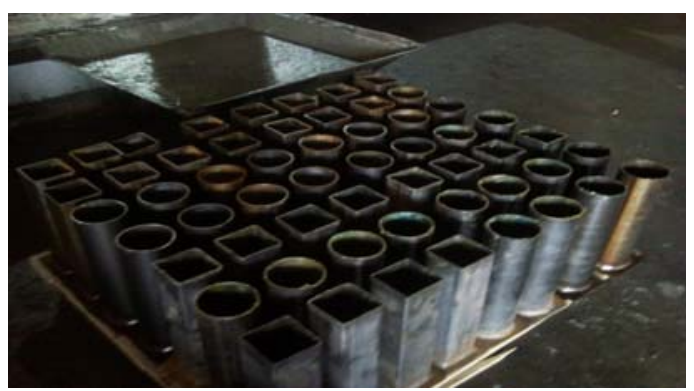

Figure 1. The Square and Circular Column Specimens before Concrete Filled

\subsection{Concrete Properties}

A batch of concrete is mixed for this study. The regular CEM I PÇ 42.5R is used as cement material in the mix. Dramix ZP 305 steel fibers with hooked ends are used in the mix at two percent $(2 \%)$ by volume. The fibers in the mix have a diameter of $0.55 \mathrm{~mm}$, length of $30 \mathrm{~mm}$, and tensile strength of $1100 \mathrm{MPa}$. Standard cylindrical $(150 \mathrm{~mm}$ x $300 \mathrm{~mm})$ concrete samples are tested in accordance to Turkish Standard TS EN 206 [9] and TS EN 12390 [10] to determine the compressive strength. The average compressive strengths of the concrete $\left(\mathrm{f}_{\mathrm{cm}}\right)$ at the time of test are $115 \mathrm{MPa}$ for cylindrical samples. Cylindrical samples are tested at a loading rate of $250 \mathrm{kN} /$ min. Water-binder (cement + silica fume) ratio is kept constant at 0.13 . The typical mix composition of the high strength concrete is given in Table 1.

Table 1. High Strength Concrete Composition

\begin{tabular}{cccccccc}
\hline \multicolumn{7}{c}{ Mix proportions kg (for $1 \mathrm{~m}^{3}$ concrete) } \\
\hline Cement & $\begin{array}{c}\text { Siliceous } \\
\text { Sand } \\
(0.5-2 \mathrm{~mm})\end{array}$ & $\begin{array}{c}\text { Siliceous } \\
\text { Powder } \\
(0-0.5 \mathrm{~mm})\end{array}$ & $\begin{array}{c}\text { Silica } \\
\text { fume }\end{array}$ & $\begin{array}{c}\text { Super } \\
\text { Plasticizer }\end{array}$ & Water & $\begin{array}{c}\text { ZP305 } \\
\text { Dramix } \\
\text { steel fiber }\end{array}$ & Total \\
\hline 1000 & 325 & 500 & 250 & 30 & 165 & 160 & 2430 \\
\hline
\end{tabular}

\section{2}

\section{Steel Properties}

All the steel tubes are manufactured from mild steel. In order to determine the actual material properties, three coupons are cut from each steel tube with different steel tube wall for the square and the circular specimens according to Turkish Standard TS 138 EN 10002 [11]. The average yield stress, tensile strength, and modulus of elasticity for the square and the circular specimens are given in Table 2 .

Table 2. The Material Properties of the Steel Tubes Obtained from the Coupon Tests

\begin{tabular}{llll}
\hline & $\left.\mathbf{f}_{\mathbf{y}} \mathbf{( M P a}\right)$ & $\left.\mathbf{f}_{\mathbf{u}} \mathbf{( M P a}\right)$ & $\left.\mathbf{E}_{\mathbf{s}} \mathbf{( M P a}\right)$ \\
\hline Square 3 mm & 300 & 369 & 200000 \\
\hline Square $4 \mathrm{~mm}$ & 304 & 375 & 200000 \\
\hline Square 5 mm & 310 & 383 & 200000 \\
\hline Circular 3 mm & 311 & 400 & 200000 \\
\hline Circular 4 mm & 306 & 389 & 200000 \\
\hline Circular 6 mm & 314 & 418 & 200000 \\
\hline
\end{tabular}


All the tests are performed at the Istanbul Technical University, Civil Engineering Department in Structure and Earthquake Laboratory. Testing of the square and the circular high strength CFST stub columns are tested using a $5000 \mathrm{kN}$ capacity INSTRON testing machine. Two linear variable differential transducers $\left(\mathrm{LVDT}_{\mathrm{s}}\right)$ are placed at diametrically opposite positions to measure the axial deformation. Four strain gauges are used for each specimen to measure strains at the middle height, two strain gauges at the top and two strain gauges at the bottom. The data is acquired at each 30 $\mathrm{kN}$ load until the yield point. After this point, data is sampled at $10 \mathrm{kN}$ intervals. The test setup is shown in Figure 2a, 2b and Figure 3a, 3b.

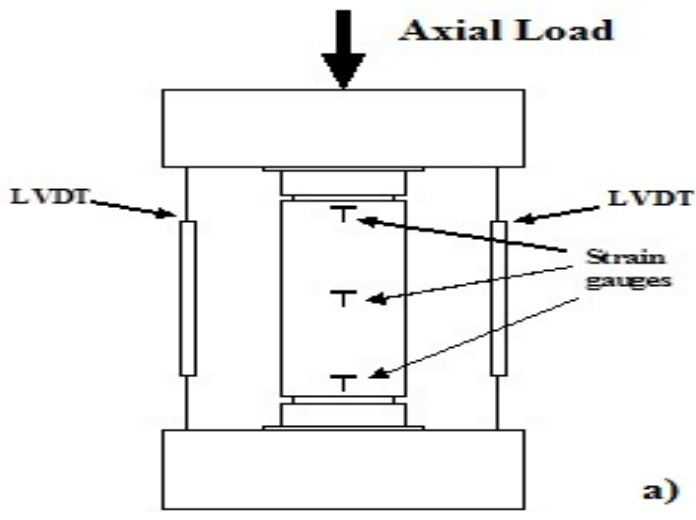

Figure 2a. The Schematic View of Test Set Up

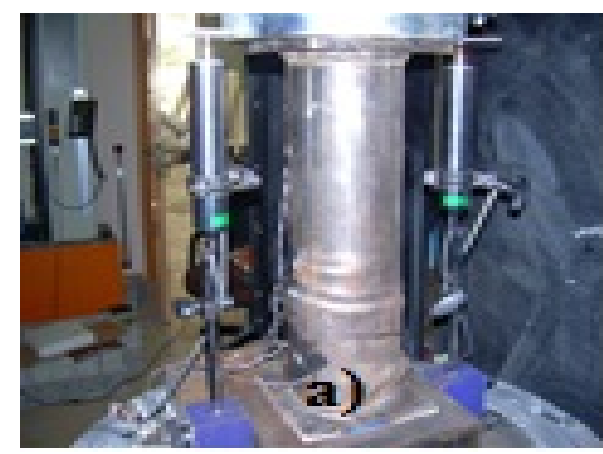

Figure 3a. The Test Setup for the Circular Columns

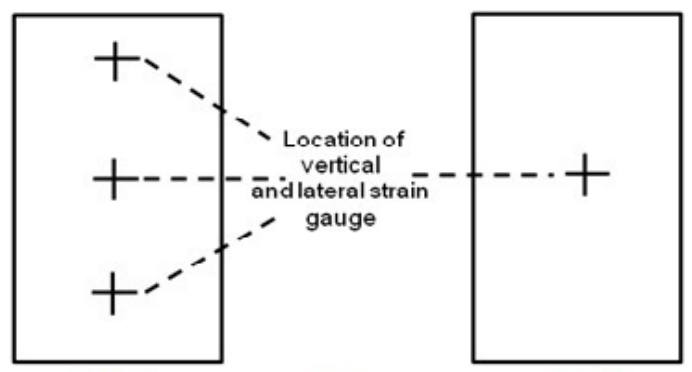

Side A

b)

Side B

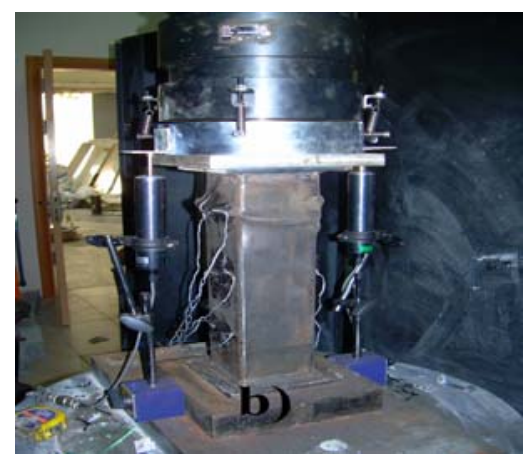

3b. The Test Setup for the Square Columns

The specimens filled with concrete are labeled according to their shape, thickness of steel tube, greased or non-greased and their order. For instance, S3G-1, denotes that the specimen is square (S), the steel tube has a thickness of $3 \mathrm{~mm}$, the specimen is greased $(\mathrm{G})$, and it is the first specimen in this group. Similarly, C5NG-2, denotes that the specimen is circular (C), the steel tube has a thickness of $5 \mathrm{~mm}$, the specimen is non-greased (NG), and it is the second specimen in this group. The square and the circular hollow specimens (unfilled concrete) were labeled similarly except the greased or the non-greased label. The test properties and the axial load capacities $\left(\mathrm{N}_{\mathrm{ue}}\right)$ obtained from the tests of the square and the circular specimens are given in Table 3 and Table 4, respectively. 
3. EXPERIMENTAL RESULTS

3.1 Loads versus Axial Shortening

Axial load - axial shortening curves for the square and the circular specimens are shown in Figures 4. As seen in these figures, all the square and the circular high strength CFST columns have no obvious axial shortening during the initial linear elastic period of the loading process, which is the cooperation of steel tube and the concrete core. When the axial load reaches about 90 to $95 \%$ of the peak load, the steel tube starts yielding, micro-cracking is initiated and propagated in concrete core, and the local buckling slightly occurs. Therefore, the axial and lateral strains measured at mid-height start to increase notably. The axial load of the square and the circular high strength CFST columns rapidly decrease after the peak load with increased axial shortenings.

As expected, the difference of the axial load capacity is much higher for the circular columns than the square ones with same steel tube wall. However, the difference of the axial load capacity is gradually reduced when the steel tube wall is increased and same for both of the square and the circular high strength CFST columns with $\mathrm{H} / \mathrm{t}$ or $\mathrm{D} / \mathrm{t}$ ratio smaller than 20 . As seen from Figures 4 , it can be clearly said that the bond effect on the axial load capacity is more and more reduced for the square and the circular high strength CFST columns with $\mathrm{H} / \mathrm{t}$ or $\mathrm{D} / \mathrm{t}$ ratio smaller than 20 . The difference of the average axial load capacity between the greased and the non-greased square and circular high strength CFST columns is shown in Figure 4, Figure 5, and Figure 6.

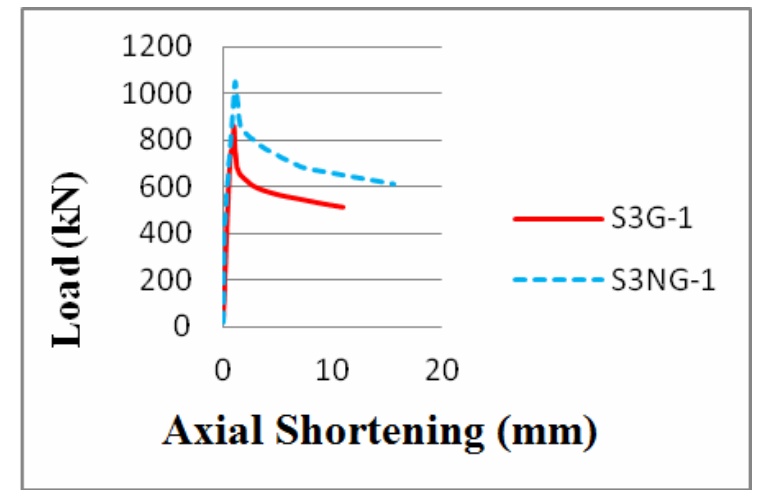

Figure 4a. The Square Columns with $3 \mathrm{~mm}$ Steel Tube Wall

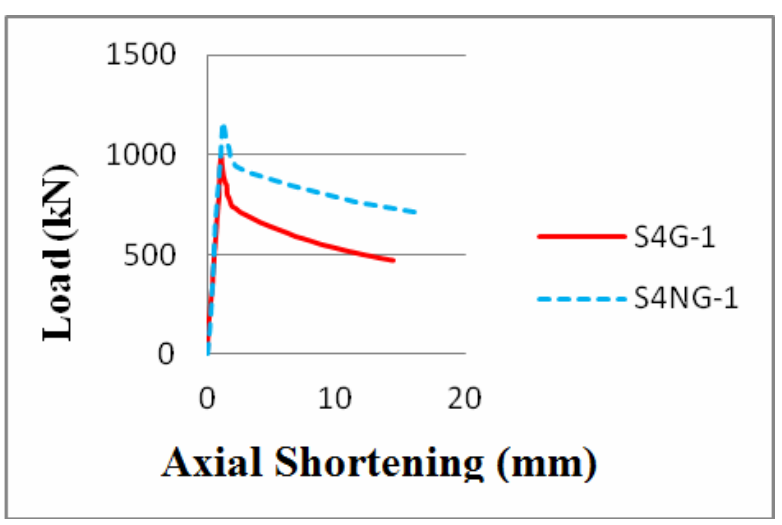

c. The Square Columns with
$4 \mathrm{~mm}$ Steel Tube Wall

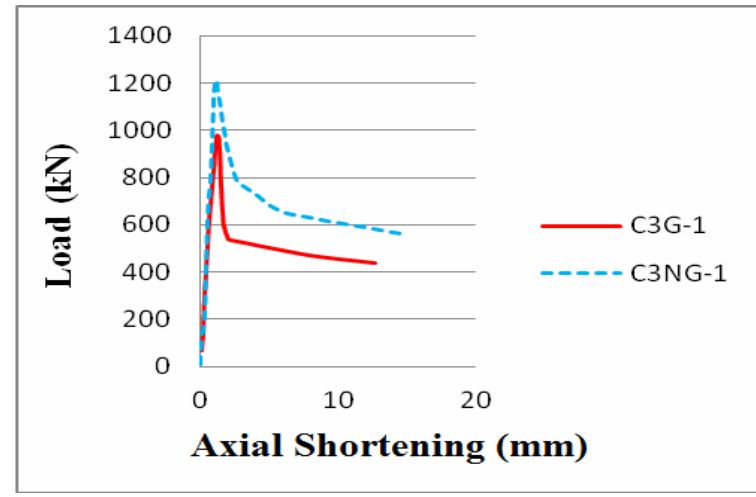

b. The Circular Columns with $3 \mathrm{~mm}$ Steel Tube Wall

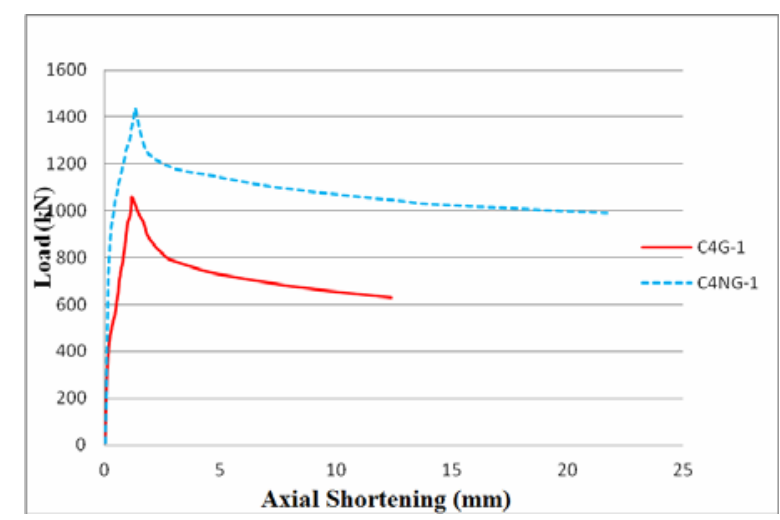

d. The Circular Columns with $4 \mathrm{~mm}$ Steel Tube Wall 


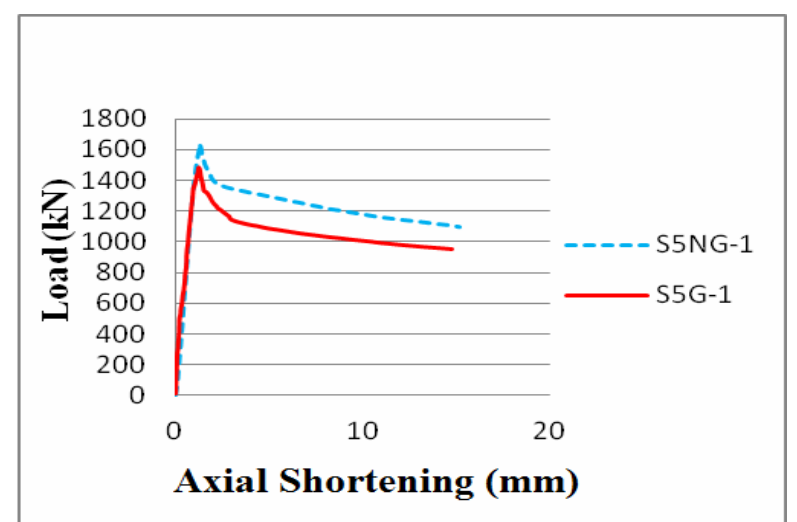

e. The Square Columns with $5 \mathrm{~mm}$ Steel Tube Wall

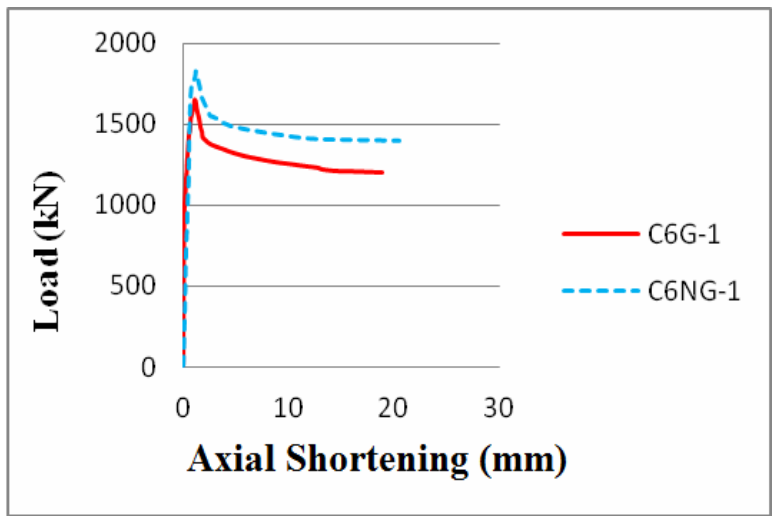

f. The circular columns with $6 \mathrm{~mm}$ steel tube wall

Table 3. Measured Square Specimen Results

\begin{tabular}{|c|c|c|c|c|c|c|c|c|}
\hline Specimen & $\mathrm{H} \times \mathrm{B} \times \mathrm{t}(\mathrm{mm})$ & $\mathrm{L}(\mathrm{mm})$ & $\mathrm{H} / \mathrm{t}$ & $\mathrm{f}_{\mathrm{cm}}(\mathrm{MPa})$ & $\mathrm{f}_{\mathrm{y}}(\mathrm{MPa})$ & $\mathrm{A}_{\mathrm{s}}\left(\mathrm{mm}^{2}\right)$ & $\mathrm{A}_{\mathrm{c}}\left(\mathrm{mm}^{2}\right)$ & $\mathrm{N}_{\mathrm{ue}}(\mathrm{kN})$ \\
\hline S3G-1 & $100.08 \times 99.86 \times 3.01$ & 400 & 33.2 & 115 & 300 & 1167 & 8827 & 856 \\
\hline S3G-2 & 100.06 × $99.91 \times 3.02$ & 400 & 33.1 & 115 & 300 & 1171 & 8826 & 920 \\
\hline S3G-3 & $100.06 \times 99.93 \times 3.01$ & 400 & 33.2 & 115 & 300 & 1168 & 8831 & 902 \\
\hline S3NG-1 & $100.08 \times 100.05 \times 3.03$ & 400 & 33 & 115 & 300 & 1176 & 8837 & 1049 \\
\hline S3NG-2 & $100.07 \times 100.06 \times 3.02$ & 400 & 33.1 & 115 & 300 & 1172 & 8841 & 1017 \\
\hline $\mathrm{S} 3 \mathrm{H}-1$ & $99.89 \times 99.95 \times 3.02$ & 400 & 33.1 & - & 300 & 1171 & - & 295 \\
\hline $\mathrm{S} 3 \mathrm{H}-2$ & $99.91 \times 99.97 \times 3.02$ & 400 & 33.1 & - & 300 & 1171 & - & 322 \\
\hline S4G-1 & $100.12 \times 100.21 \times 3.97$ & 400 & 25.2 & 115 & 304 & 1528 & 8505 & 990 \\
\hline S4G-2 & $100.06 \times 100.08 \times 3.99$ & 400 & 25.1 & 115 & 304 & 1533 & 8481 & 980 \\
\hline S4NG-1 & $101.05 \times 101.23 \times 3.98$ & 400 & 25.4 & 115 & 304 & 1547 & 8683 & 1160 \\
\hline S4NG-2 & $101.03 \times 101.08 \times 4.01$ & 400 & 24.9 & 115 & 304 & 1556 & 8656 & 1100 \\
\hline $\mathrm{S} 4 \mathrm{H}-1$ & $99.96 \times 99.87 \times 4.02$ & 400 & 24.9 & - & 304 & 1542 & - & 442 \\
\hline $\mathrm{S} 4 \mathrm{H}-2$ & $99.95 \times 99.84 \times 4.01$ & 400 & 24.9 & - & 304 & 1538 & - & 460 \\
\hline S5G-1 & $100.02 \times 101.04 \times 4.98$ & 400 & 20.1 & 115 & 310 & 1903 & 8201 & 1481 \\
\hline S5G-2 & $100.05 \times 101.23 \times 4.97$ & 400 & 20.1 & 115 & 310 & 1902 & 8226 & 1474 \\
\hline S5NG-1 & $100.11 \times 100.16 \times 5.02$ & 400 & 19.9 & 115 & 310 & 1910 & 8117 & 1642 \\
\hline S5NG-2 & $100.17 \times 100.21 \times 4.97$ & 400 & 20.2 & 115 & 310 & 1893 & 8145 & 1636 \\
\hline S5H-1 & $99.97 \times 99.88 \times 5.05$ & 400 & 19.8 & - & 310 & 1916 & - & 685 \\
\hline $\mathrm{S} 5 \mathrm{H}-2$ & $99.96 \times 99.87 \times 5.02$ & 400 & 19.9 & - & 310 & 1905 & - & 712 \\
\hline
\end{tabular}

Table 4. Measured Circular Specimen Results

\begin{tabular}{|c|c|c|c|c|c|c|c|c|}
\hline Specimen & $\mathrm{D} \times \mathrm{t}(\mathrm{mm})$ & $\mathrm{L}(\mathrm{mm})$ & $\mathrm{D} / \mathrm{t}$ & $\mathrm{fcm}(\mathrm{MPa})$ & $\mathrm{fy}_{\mathrm{y}}(\mathrm{MPa})$ & $\mathrm{As}_{\mathrm{s}}\left(\mathrm{mm}^{2}\right)$ & $\mathrm{Ac}_{\mathrm{c}}\left(\mathrm{mm}^{2}\right)$ & Nue $(\mathrm{kN})$ \\
\hline C3G-1 & $114.24 \times 3.02$ & 400 & 37.8 & 115 & 311 & 1055 & 9190 & 980 \\
\hline C3G-2 & $114.21 \times 3.02$ & 400 & 37.8 & 115 & 311 & 1054 & 9185 & 909 \\
\hline C3G-3 & $114.19 \times 3.01$ & 400 & 37.9 & 115 & 311 & 1051 & 9185 & 940 \\
\hline C3NG-1 & $114.26 \times 3.02$ & 400 & 37.8 & 115 & 311 & 1055 & 9194 & 1214 \\
\hline C3NG-2 & $114.23 \times 3.02$ & 400 & 37.8 & 115 & 311 & 1055 & 9188 & 1233 \\
\hline C3H-1 & $114.21 \times 3.03$ & 400 & 37.7 & - & 311 & 1058 & - & 402 \\
\hline C3H-2 & $114.24 \times 2.99$ & 400 & 38.2 & - & 311 & 1044 & - & 416 \\
\hline C4G-1 & $114.18 \times 3.98$ & 400 & 28.6 & 115 & 306 & 1377 & 8857 & 1060 \\
\hline C4G-2 & $114.22 \times 3.99$ & 400 & 28.7 & 115 & 306 & 1381 & 8860 & 1221 \\
\hline C4G-3 & $114.27 \times 3.98$ & 400 & 28.5 & 115 & 306 & 1378 & 8872 & 1116 \\
\hline C4NG-1 & $114.29 \times 4.01$ & 400 & 28.5 & 115 & 306 & 1389 & 8865 & 1436 \\
\hline C4NG-2 & $114.26 \times 4.02$ & 400 & 28.4 & 115 & 306 & 1392 & 8857 & 1315 \\
\hline C4NG-3 & $114.23 \times 4.01$ & 400 & 28.5 & 115 & 306 & 1388 & 8855 & 1420 \\
\hline C4H-1 & $114.27 \times 4.02$ & 400 & 28.4 & - & 306 & 1392 & - & 624 \\
\hline C4H-2 & $114.25 \times 4.01$ & 400 & 28.5 & - & 306 & 1388 & - & 642 \\
\hline C6G-1 & $114.21 \times 5.99$ & 400 & 19.1 & 115 & 314 & 2035 & 8204 & 1650 \\
\hline C6G-2 & $114.28 \times 5.98$ & 400 & 19.1 & 115 & 314 & 2034 & 8219 & 1615 \\
\hline C6NG-1 & $114.32 \times 5.98$ & 400 & 19.1 & 115 & 314 & 2034 & 8225 & 1830 \\
\hline C6NG-2 & $114.33 \times 5.98$ & 400 & 19.1 & 115 & 314 & 2035 & 8226 & 1810 \\
\hline C6H-1 & $114.28 \times 6.02$ & 400 & 19 & 115 & 314 & 2046 & - & 832 \\
\hline C6H-2 & $114.27 \times 6.02$ & 400 & 19 & 115 & 314 & 2046 & - & 850 \\
\hline & & & & & & & & \\
\hline
\end{tabular}




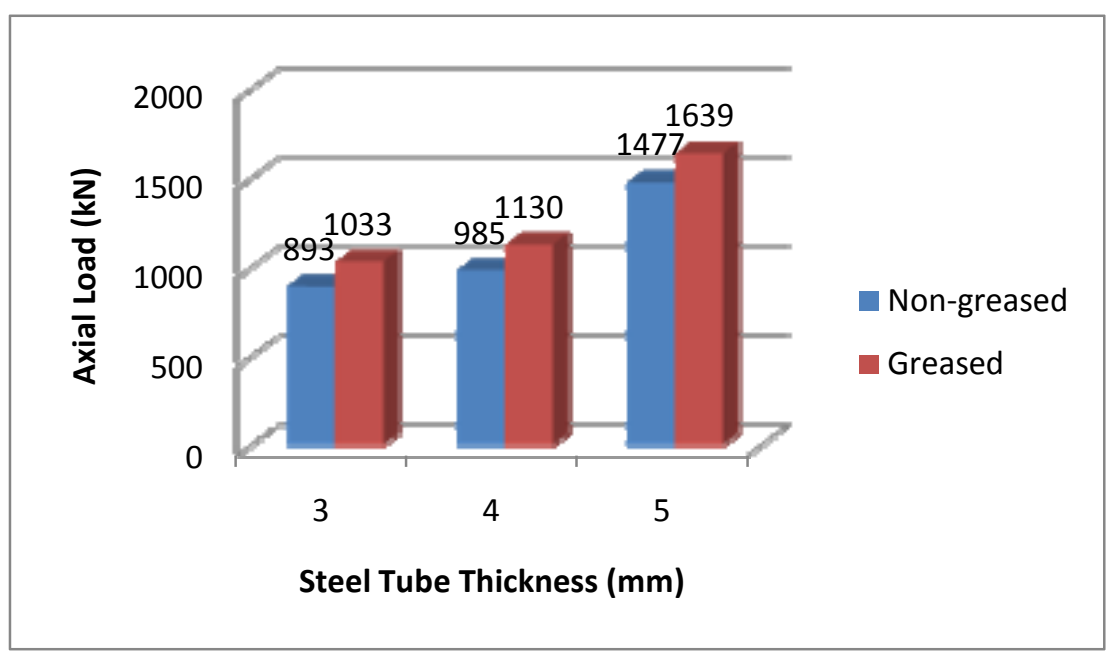

Figure 5. The Difference of the Average Axial Load Capacity for the Greased and the Non-greased Square Specimens

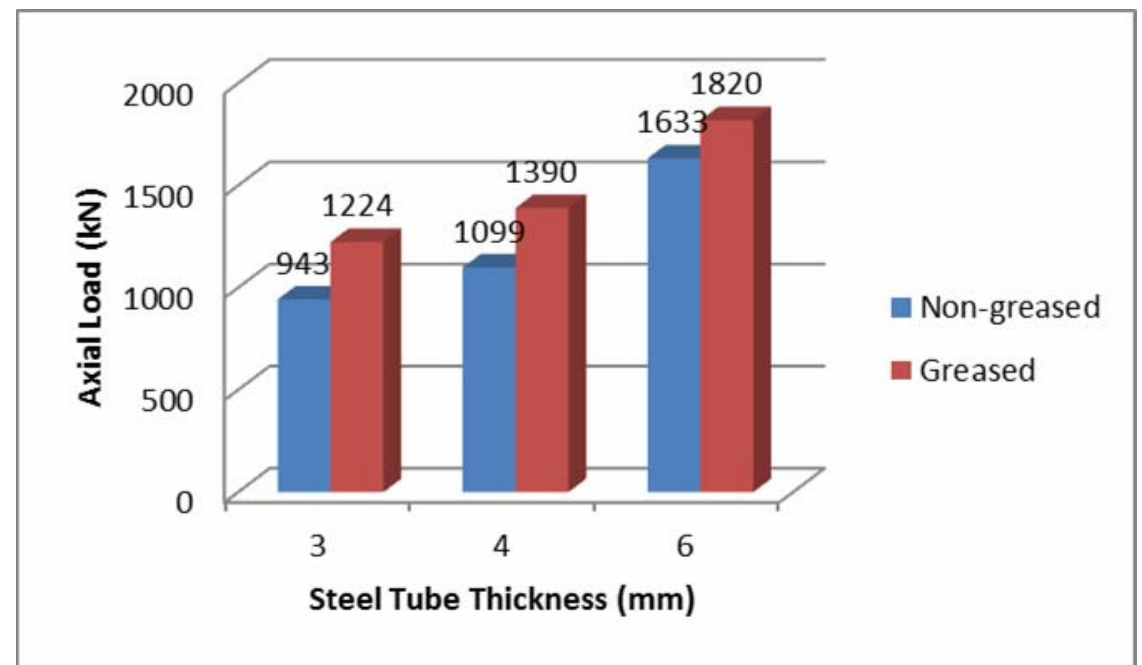

Figure 6. The Difference of the Average Axial Load Capacity for the Greased and the Non-greased Circular Specimens

Performance Indices

Some important parameters are defined to compare the ductility and the strength enhancement of the CFST columns by Han et al. [12]; and Yang et al. [13]. Those parameters are the ductility index (DI), the strength enhancement index (SI), and the concrete contribution ratio (CCR). They are defined from Eq.1 to Eq.3.

$$
\begin{aligned}
& D I=\frac{\delta_{85 \%}}{\delta_{u}} \\
& S I=\frac{N_{u, \text { filled }}}{A_{s} f_{y}+A_{c} f_{c k}}
\end{aligned}
$$




$$
\text { CCR }=\frac{N_{u, \text { filled }}}{N_{u, \text { hollow }}}
$$

Here, $\mathrm{N}_{\mathrm{u} \text {,filled }}$ is the ultimate load reached in the tests; $\mathrm{N}_{\mathrm{u}}$, hollow is the ultimate load of the un-filled steel tubes; $\delta_{u}$ is the axial shortening at the ultimate load; $\delta_{85 \%}$ is the axial shortening when the load falls to $85 \%$ of the ultimate load; $A_{s}$ and $A_{c}$ is the cross-sectional area of the steel tube and the concrete, respectively; $f_{y}$ and $f_{c k}$ is the yielding stress of the steel tube and the characteristic compressive strength of the concrete, respectively.

The ductility of the specimens is assessed in terms of the ductility index (DI) depicted in Eqn.1. The strength enhancement index (SI) can be described as the ratio the axial load capacity of the composite section to the sum of the strengths of the steel tube and the concrete core. The level of strength enhancement arising from the concrete filling is represented by the CCR that is defined as the ratio the maximum load of composite column to the hollow column. The relationships between the constraining factor and the ductility index, strength enhancement index and the concrete contribution ratio are shown in Figures 6.

As seen from Figures 7 and Table 5, there is a significant increase in the DI when the D/t ratio is reduced for both of the square and the circular CFST columns. However, the increase in the DI is notably higher for the circular CFST columns than the square ones. The average increase in the DI for the square and the circular columns, compared with the $3 \mathrm{~mm}$ and $5 \mathrm{~mm}$ and $6 \mathrm{~mm}$ steel tube wall, is $29 \%$ and $63 \%$, respectively. This proves that when the $\mathrm{D} / \mathrm{t}$ ratio of both of the high strength CFST columns is reduced, the circular high strength CFST columns significantly exhibit more ductile behavior than the square ones after the peak load. Similarly, there is a significant increase in the SI when the $\mathrm{H} / \mathrm{t}$ or $\mathrm{D} / \mathrm{t}$ ratio of the square and the circular high strength CFST columns is reduced. However, the increase in the SI is only valid for the square and the circular CFST columns with $5 \mathrm{~mm}$ and $6 \mathrm{~mm}$ steel tube wall. As seen, there is no any enhancement in the SI for the thinner ( $3 \mathrm{~mm}$ and $4 \mathrm{~mm}$ ) CFST columns. Compared with the increase in the DI, the increase in the SI is slightly larger for the circular columns than the square ones. The average increase in the SI for the square and the circular high strength CFST columns, compared with the 3 $\mathrm{mm}$ and $5 \mathrm{~mm}$ or $6 \mathrm{~mm}$ steel tube wall, is $38 \%$ and $48 \%$, respectively. Contrary to the DI and the SI performance indices, the CCR performance indices that represent the benefit of concrete filling into the hollow steel tube is much more critical for the square high strength CFST columns than the circular ones. The average increase in the CCR for the square and the circular columns, steel tube wall is reduced from $6 \mathrm{~mm}$ or $5 \mathrm{~mm}$ to $3 \mathrm{~mm}, 41 \%$ and $22 \%$, respectively. This is due to fact that the square hollow steel tubes are more vulnerable to local buckling and has significantly smaller axial load capacities than the circular ones. Furthermore, compared with the same steel tube wall, the non-greased square and the circular CFST columns have higher performance indices than the greased ones due to stronger bond effect between the steel tube and the concrete core. 
Table 5. Values of Performance Indices

\begin{tabular}{|c|c|c|c|c|c|c|c|}
\hline Specimen & DI & SI & CCR & Specimen & DI & SI & CCR \\
\hline S3G-1 & 1.28 & 0.62 & 2.74 & C3G-1 & 1.39 & 0.71 & 2.08 \\
\hline S3G-2 & 1.32 & 0.67 & 2.95 & C3G-2 & 1.36 & 0.66 & 1.93 \\
\hline S3G-3 & 1.3 & 0.66 & 2.89 & C3G-3 & 1.38 & 0.68 & 2.00 \\
\hline S3NG-1 & 1.41 & 0.77 & 3.36 & C3NG-1 & 1.42 & 0.88 & 2.58 \\
\hline S3NG-2 & 1.38 & 0.74 & 3.26 & C3NG-2 & 1.46 & 0.89 & 2.62 \\
\hline S4G-1 & 1.51 & 0.69 & 2.36 & C4G-1 & 1.67 & 0.74 & 1.68 \\
\hline S4G-2 & 1.49 & 0.68 & 2.33 & C4G-2 & 1.7 & 0.85 & 1.93 \\
\hline S4NG-1 & 1.61 & 0.8 & 2.76 & C4G-3 & 1.69 & 0.77 & 1.77 \\
\hline S4NG-2 & 1.58 & 0.76 & 2.62 & C4NG-1 & 1.79 & 0.99 & 2.27 \\
\hline S5G-1 & 1.71 & 0.98 & 2.08 & C4NG-2 & 1.81 & 0.91 & 2.08 \\
\hline S5G-2 & 1.69 & 0.97 & 2.07 & C4NG-3 & 1.83 & 0.98 & 2.25 \\
\hline S5NG-1 & 1.74 & 1.09 & 2.31 & C6G-1 & 2.23 & 1.05 & 1.79 \\
\hline S5NG-2 & 1.78 & 1.08 & 2.30 & C6G-2 & 2.21 & 1.03 & 1.75 \\
\hline & & & & C6NG-1 & 2.38 & 1.17 & 1.98 \\
\hline & & & & C6NG-2 & 2.36 & 1.16 & 1.96 \\
\hline
\end{tabular}

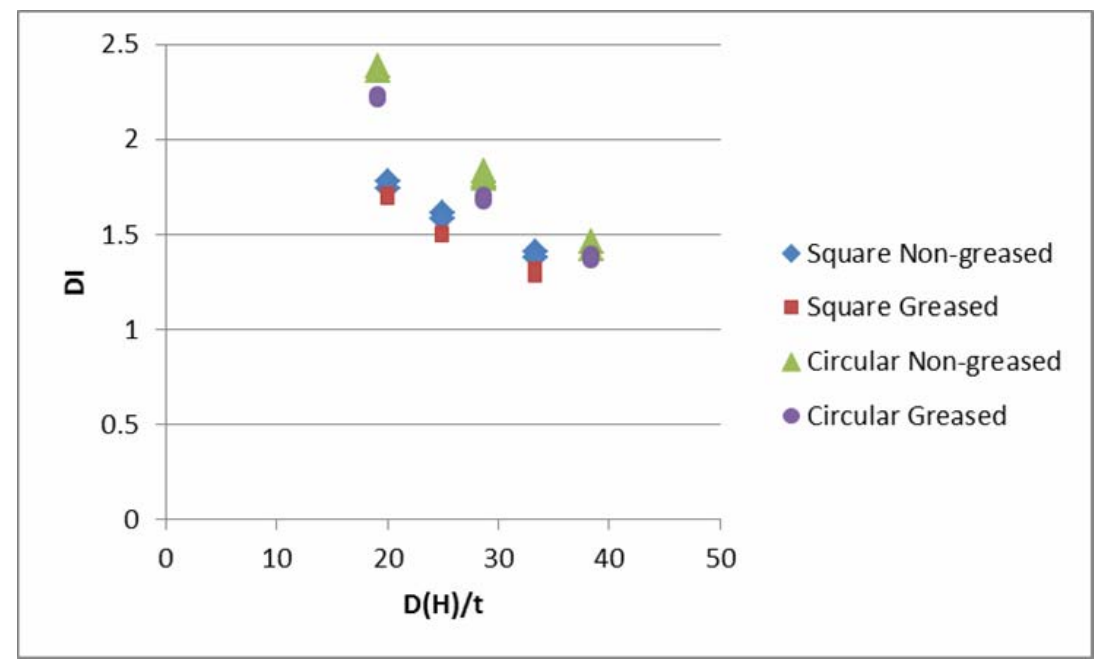

Figure 7a. DI versus D (H)/t Relationship 


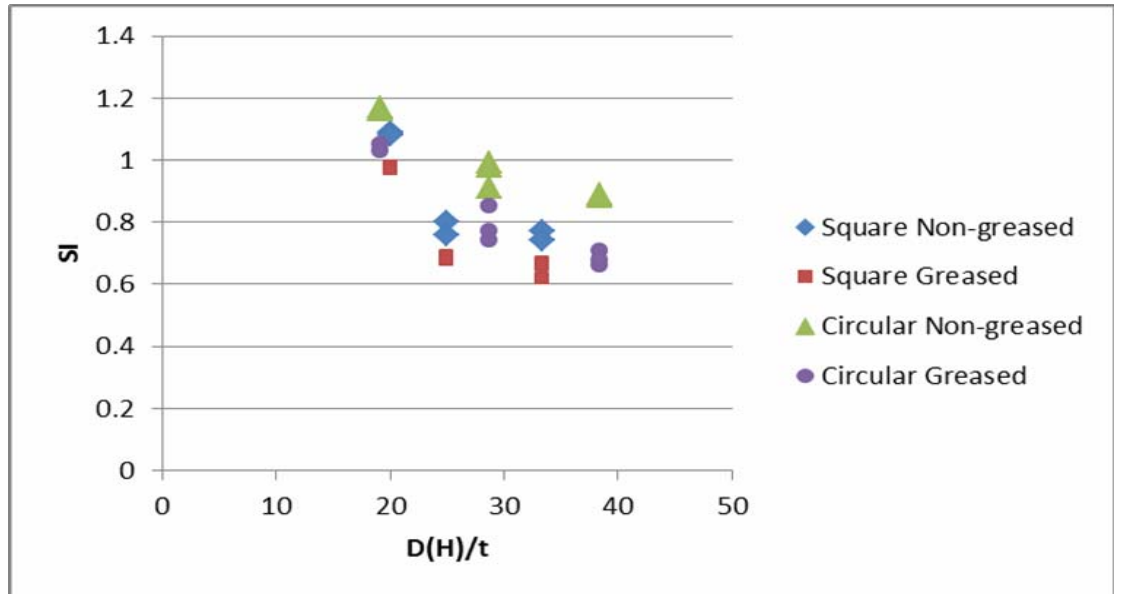

Figure $7 b$. SI versus $\mathrm{D}(\mathrm{H}) / \mathrm{t}$ Relationship

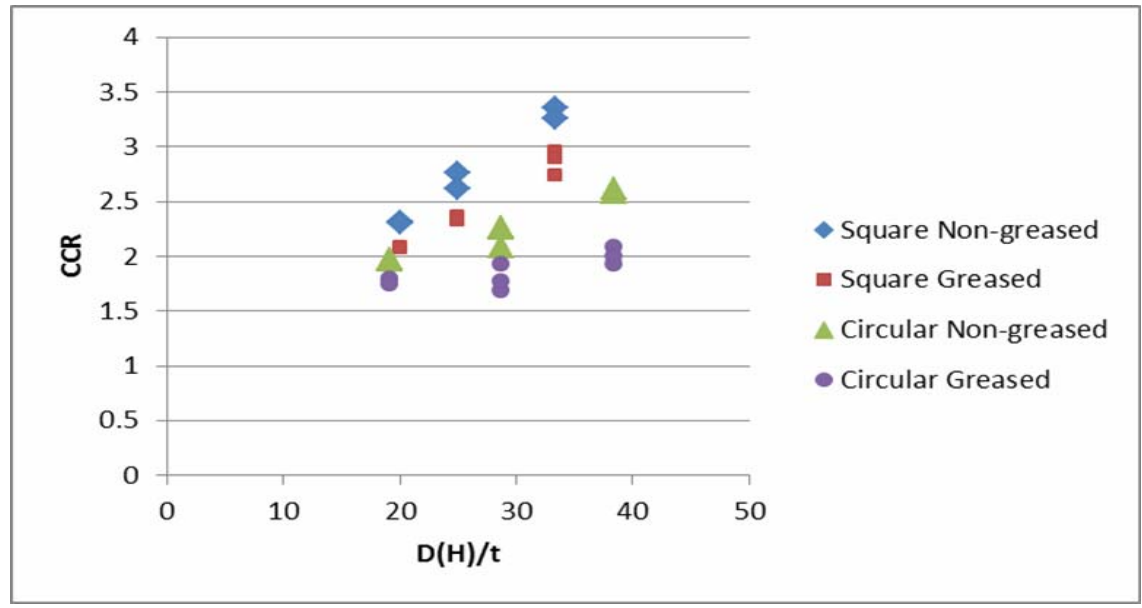

Figure 7c. CCR versus D(H)/t Relationship

\section{4.}

\section{DESIGN CODES}

\subsection{Eurocode 4:}

The EC4 (2004) design code is the most lately completed international standard in composite construction. EC4 covers concrete encased and partially encased steel sections and concrete- filled sections with or without reinforcement. The EC4 approach is limited to CFST columns with concrete strength of $50 \mathrm{MPa}$. The axial load capacity of the square CFST columns according to the EC4 is given by Eq. 4 :

$$
N_{u, E C 4}=A_{c} f_{c k}+A_{s} f_{y}
$$

The EC4 takes account the confining effect by the steel tube calculating the axial load capacity of the circular CFST columns. If the relative slenderness does not exceed 0.5 and e/D is smaller than 0.1, the axial load capacity of the circular CFST columns can be calculated from Eq.5 to 11:

$$
N_{u, E C 4}=\left(1+\eta_{c} \frac{t}{D} \frac{f_{y}}{f_{c k}}\right) f_{c k} A_{c}+\eta_{a} f_{y} A_{s}
$$




$$
\begin{array}{ll}
\eta_{c}=4.9-18.5 \lambda+17 \lambda^{2} & \left(\mathrm{\eta}_{\mathrm{c}} \geq 0\right) \\
\eta_{a}=0.25(3+2 \lambda) & \left(\mathrm{\eta}_{\mathrm{a}} \leq 1\right) \\
\lambda=\sqrt{\frac{N_{p l, R}}{N_{c r}}} \leq 0.5 & \\
N_{p l, R}=A_{c} f_{c k}+A_{s} f_{y} & \\
N_{c r}=\frac{\pi^{2}(E I)_{e}}{l^{2}} & \\
(E I)_{e}=A_{s} E_{s}+0.6 E_{c m} A_{c} &
\end{array}
$$

Here, $\eta_{c}$ is the coefficient of confinement for the concrete; $\eta_{\mathrm{a}}$ is the coefficient of confinement for the steel tube; $\lambda$ is the relative slenderness; 1 is the buckling length of the CFST column; $E_{\mathrm{cm}}$ is the secant elastic modulus of concrete; $(E I)_{e}$ is the effective flexural stiffness; $f_{c k}$ is the characteristic concrete cylinder strength,; and $\mathrm{f}_{\mathrm{y}}$ is the yield strength of the steel.

As seen from Table 6 and Figure 8, although the EC4 overestimate the axial load capacity for the square and the circular high strength CFST columns with thinner steel tube wall (especially nominal $\mathrm{D} / \mathrm{t}$ or $\mathrm{H} / \mathrm{t}$ is greater than 33 ), it can reliably predict the axial load capacity for the square and the circular high strength CFST columns with nominal D/t or H/t ratio smaller than 20 . In addition, due to loss of bonding and little confinement by the steel tubes, the axial load capacity of greased the square and the circular high strength CFST columns obtained from test results, compared with the non-greased columns, are lower than the values predicted by the EC4. This difference is much greater for the columns with the thinner steel tube wall than the thicker ones. Furthermore, the EC4 is more conservative for the square high strength CFST columns than the circular ones. This is due to the fact that although the EC4 take account the confinement effect of the steel tube to the concrete core for the circular high strength CFST columns, it doesn't consider the confinement effect for the square ones. The average $\mathrm{N}_{\mathrm{ue}} / \mathrm{N}_{\mathrm{u}, \mathrm{EC} 4}$ for greased the square and the circular CFST columns is 0.75 and 0.62 , respectively. In addition, the average $\mathrm{N}_{\mathrm{ue}} / \mathrm{N}_{\mathrm{u}, \mathrm{EC} 4}$ for non-greased the square and the circular columns is 0.87 and 0.79 , respectively.

\subsection{AISC-LRFD}

The axial load capacity of the square and the circular CFST columns according to AISC-LRFD (1999) design code is given from Eq.12 to Eq.16:

$$
\begin{aligned}
& F_{m y}=f_{y}+0.85 f_{c}\left(A_{c} / A_{s}\right) \\
& E_{m}=E_{S}+0.4 E_{c}\left(A_{c} / A_{s}\right) \\
& \lambda_{c}=\frac{K L}{\pi r_{m}} \sqrt{\frac{F_{m y}}{E_{m}}}
\end{aligned}
$$


$F_{c r}=0.658^{\lambda_{c}^{2}} F_{m y}$

$N_{u}=A_{s} F_{c r}$

As seen From Table 6 and Figure 9, it can be said that the AISC-LRFD, similarly EC4, is not safe for the square and the circular columns with the thinner steel tube wall compared to the thicker ones. The average Nue / Nu, AISC-LRFD for the greased square and the circular columns is 0.97 and 1.05, respectively. In addition, the average Nue / $\mathrm{Nu}$, AISC-LRFD for the non-greased square and the circular columns is 1.12 and 1.28, respectively. The axial load capacities obtained from the test results for the square and the circular high strength CFST columns are compared with the values predicted by the EC4 and the AISC-LRFD is given in Table 7, Figure 8, and Figure 9.

Table 6. Comparisons of Axial Load Capacities between Test Results and Design Codes

\begin{tabular}{llll}
\hline Specimen No & $\mathbf{N}_{\mathbf{u e}(\mathbf{k N})}$ & $\mathbf{N}_{\mathbf{u e}} / \mathbf{N}_{\mathbf{u}, \text { EC4 }}$ & $\mathbf{N}_{\mathbf{u e}} / \mathbf{N}_{\mathbf{u}, \text { AISC }}$ \\
\hline S3G-1 & 856 & 0.63 & 0.82 \\
\hline S3G-2 & 920 & 0.67 & 0.88 \\
\hline S3G-3 & 902 & 0.66 & 0.87 \\
\hline S3NG-1 & 1049 & 0.77 & 1.00 \\
\hline S3NG-2 & 1017 & 0.74 & 0.97 \\
\hline S4G-1 & 990 & 0.69 & 0.88 \\
\hline S4G-2 & 980 & 0.68 & 0.88 \\
\hline S4NG-1 & 1160 & 0.79 & 1.02 \\
\hline S4NG-2 & 1100 & 0.75 & 0.97 \\
\hline S5G-1 & 1481 & 0.97 & 1.23 \\
\hline S5G-2 & 1474 & 0.96 & 1.22 \\
\hline S5NG-1 & 1642 & 1.08 & 1.37 \\
\hline S5NG-2 & 1636 & 1.07 & 1.37 \\
\hline Mean & & 0.8 & 1.04 \\
\hline St.Dev. & & 0.15 & 0.19 \\
\hline
\end{tabular}

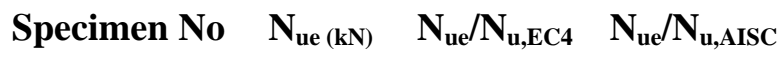

\begin{tabular}{llll} 
C3G-1 & 980 & 0.59 & 0.93 \\
\hline C3G-2 & 909 & 0.55 & 0.87 \\
\hline C3G-3 & 940 & 0.56 & 0.90 \\
\hline C3NG-1 & 1214 & 0.73 & 1.16 \\
\hline C3NG-2 & 1233 & 0.74 & 1.17 \\
\hline C4G-1 & 1060 & 0.59 & 0.96 \\
\hline C4G-2 & 1221 & 0.68 & 1.10 \\
\hline C4G-3 & 1116 & 0.62 & 1.01 \\
\hline C4NG-1 & 1436 & 0.80 & 1.29 \\
\hline C4NG-2 & 1315 & 0.73 & 1.18 \\
\hline C4NG-3 & 1420 & 0.79 & 1.28 \\
\hline C6G-1 & 1650 & 0.79 & 1.32 \\
\hline C6G-2 & 1615 & 0.77 & 1.29 \\
\hline C6NG-1 & 1830 & 0.88 & 1.46 \\
\hline C6NG-2 & 1810 & 0.87 & 1.45 \\
\hline Mean & & 0.71 & 1.16 \\
\hline St. Dev. & & 0.11 & 0.19 \\
\hline
\end{tabular}

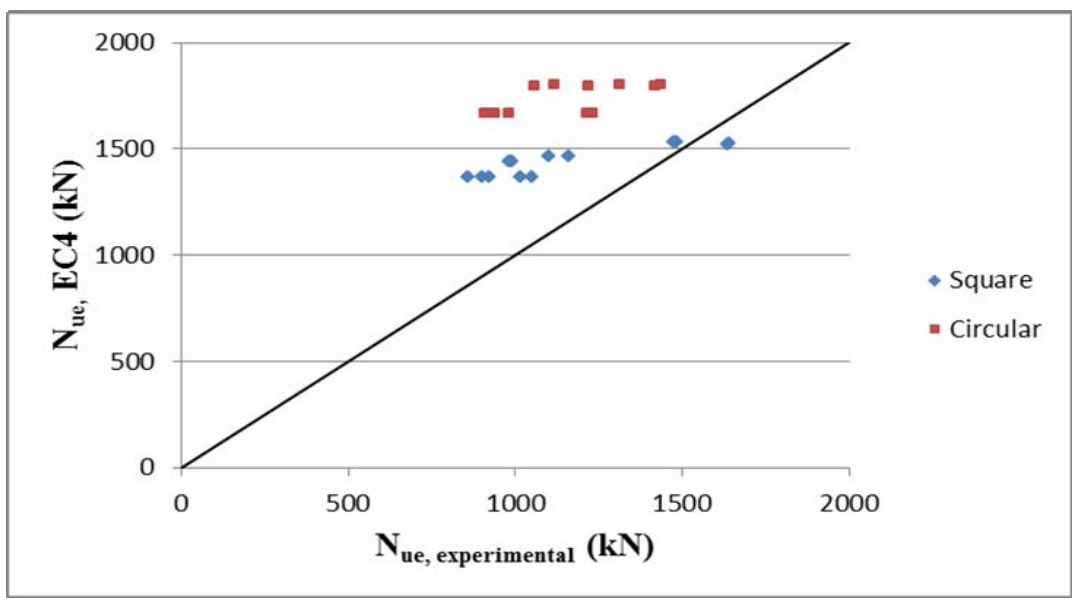

Figure 8. Comparison of test results with EC4 


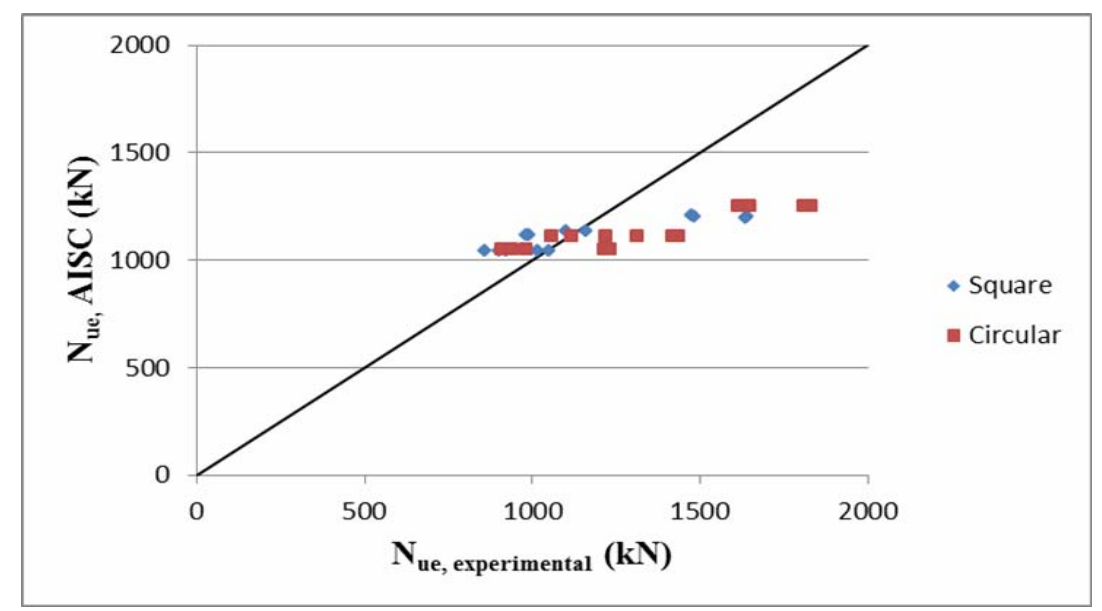

Figure 9. Comparison of Test Results with AISC-LRFD

\section{5.}

\section{CONCLUSIONS}

The present study is an attempt to investigate the bond effect on axial load capacity and performance indices of axially loaded the square and the circular high strength CFST columns with regard to different steel tube thickness. The test results are also compared with the results of present design codes such as the EC4 and the AISC-LRFD. The main conclusions obtained from this study can be drawn as below:

As known, plastic, autogenous, and drying shrinkage of high strength concrete is higher than low and normal strength concrete. As a result of this, the bond stresses between the steel tube and the concrete core is weaker for the high strength CFST columns than the low and normal strength CFST columns. Thus, the reduction on the axial load capacity due to loss of bonding is not negligible for both of the square and the circular high strength CFST columns. Furthermore, the circular high strength CFST columns have higher bond stress capacity than the square ones. As a result of this study, the $\mathrm{D}(\mathrm{H}) / \mathrm{t}$ ratio of 20 may be considered as a separation point for the bond effect on the axial load capacity of the square and the circular high strength CFST columns. The biggest difference of the axial load capacity for the circular and the square high strength CFST columns is $23 \%$ and $14 \%$, respectively.

To decrease the $\mathrm{D}(\mathrm{H}) / \mathrm{t}$ ratio significantly improves the ductility performance of the square and the circular high strength CFST columns. However, there is no much benefit to enhance the axial load capacity of the square and the circular high strength CFST columns. Hence, enhancement in ductility is more pronounced than gain in axial load capacity for both of the square and the circular high strength CFST columns. This proves that the square and the circular high strength CFST columns exhibit more ductile behaviour peculiarly after the peak load when the $D(H) / t$ ratio is reduced. The average increase in the DI and the SI performance indices for the square and the circular high strength CFST columns, steel tube wall is increased from $3 \mathrm{~mm}$ to $5 \mathrm{~mm}$ or $6 \mathrm{~mm}$, is $29 \%$ and $63 \% ; 38 \%$ and $48 \%$, respectively.

The square hollow steel tubes are much more vulnerable to local buckling and much less confinement effect to the concrete core than the circular ones. Hence, the benefit of concrete filling, as indicated by the CCR, is much more critical for the square sections than the circular ones. The average increase in the CCR for the square and the circular high strength CFST columns, steel tube wall reduced from $6 \mathrm{~mm}$ or $5 \mathrm{~mm}$ to $3 \mathrm{~mm}$, is $41 \%$ and $22 \%$, respectively. 
The EC4 design code take into account the confinement effect by the steel tube to the concrete core if the relative slenderness does not exceed 0.5 and e/D is smaller than 0.1 . The EC4 approach is limited to CFST columns with concrete strength of $50 \mathrm{MPa}$. Based on the test results, the EC4 overestimate the axial load capacity of the square and the circular high strength CFST columns. However, when the $\mathrm{D}(\mathrm{H}) / \mathrm{t}$ ratio decrease, the EC4 is more conservative and reliable to predict the axial load capacity of the high strength CFST columns. Besides, due to radial expansion of the concrete and, thus, effective confinement by the steel tube to the concrete core occurs in the circular sections, the EC4 is safer for predicting the axial load capacity of the circular high strength CFST columns than the square ones. Furthermore, the EC4 limitation on concrete cylinder strength cannot be safely extended to concrete compressive strength of over $100 \mathrm{MPa}$. The EC4 may use a reduction coefficient to consider the weak confinement effect of the steel tube to the concrete core and obtain a better agreement with the test results. The biggest difference between the test results and the EC4 for the square and the circular specimens is $37 \%$ and $41 \%$, respectively.

The AISC-LRFD is too conservative for predicting the axial load capacity of the square and the circular high strength CFST columns with $\mathrm{D}(\mathrm{H}) / \mathrm{t}$ ratio smaller than 20 . However, the predictions of this design code are not safe when the $\mathrm{D}(\mathrm{H}) / \mathrm{t}$ ratio increase. The biggest difference between test results and the AISC-LRFD design codes for the square and the circular specimens is $37 \%$ and $46 \%$, respectively.

\section{REFERENCES}

[1] Lu, Z.H. and Zhao, Y.G., "Mechanical Behavior and Ultimate Strength of Circular CFT Columns Subjected to Axial Compression Load", The 14th World Conference on Earthquake Engineering, Beijing, China, 2008.

[2] Shah, A.A. and Ribakov, Y., "Recent Trends in Steel Fibered High-strength Concrete", Materials and Design, 2011, Vol. 32, No. 8-9, pp. 412-415.

[3] Roeder, C.W., Cameron, B. and Brown, C.B., "Composite Action in Concrete Filled Tubes", Journal of Structural Engineering, ASCE, 1998, Vol. 125, No. 5, pp. 477-484.

[4] Johansson, M. and Gylltoft, K., "Mechanical Behavior of Circular Steel-concrete Composite Stub Columns", Journal of Structural Engineering, ASCE, 2002, Vol. 128, No. 8, pp. 1073-1081.

[5] Giakoumelis, G. and Lam, D., "Axial Capacity of Circular Concrete-filled Tube Columns", Journal of Constructional Steel Research, 2004, Vol. 60, No. 7, pp.1049-68.

[6] Guler, S., Lale, E. and Aydoğan, M., "Behaviour of SFRC Filled Steel Tube Columns under Axial Load", International Journal of Advanced Steel Construction, 2013, Vol. 9, No. 1, pp. $14-25$

[7] Eurocode 4 "Design of Composite Steel and Concrete Structures, Part 1.1, General R $\backslash$ rules and Rules for Buildings", EN 1994-1-1, European Committee for Standardization: British Standards Institution, 2004.

[8] American Institute of Steel Construction, AISC, "Load and Resistance Factor Design Specification for Structural Steel Buildings", American Institute of Steel Construction, Chicago, IL, 1999.

[9] Turkish Standard Institution, TS EN 206. "Concrete-Part 1: Specification, Performance, Production and Conformity", Ankara,Turkey, 2002.

[10] Turkish Standard Institution, TS EN 12390, "Testing Hardening Concrete- Part 1, Shape, Dimensions and Other Requirements for Specimens and Moulds", Ankara, Turkey, 2002.

[11] Turkish Standards Institution, TS 138 EN 10002-1, "Metallic Materials - Tensile Testing Part 1", Ankara, Turkey, 2004.

[12] Han, L.H., "Tests on Stub Columns of Concrete-filled RHS Sections", Journal of Constructional Steel Research, 2002, Vol. 58, No. 2, pp. 353-72.

[13] Yang, H., Lam, D. and Gardner, L. "Testing and Analysis of Concrete-filled Elliptical Hollow Sections”, Engineering Structures,2008, Vol. 30, No. 12, pp. 3771-3781. 